\title{
Advantages of working in the developing world during paediatric training
}

\author{
C J C Williams
}

\section{Background}

After three years as a paediatric senior house officer in the north of England, I volunteered to work for nine months in Wau, southern Sudan, with Médecins Sans Frontières as part of the international relief effort. The experience and knowledge gained, both medical and in personal terms, are described in this article in the hope of encouraging more doctors to take time out to work in developing countries.

Southern Sudan has been intermittently in open rebellion against the north since gaining independence from Britain in the 1950s. The black and mainly Christian or Animist southerners have been unhappy with political and religious domination from the Islamic north, especially attempts to impose Sharia (Islamic law) since 1983. The Sudanese People's Liberation Army (SPLA) now controls most of the rural areas of southern Sudan except for some of the larger towns where the northern army maintains large garrisons.

During the 1988 disruption of agricultural production and supply by the fighting created a large refugee population with malnutrition and starvation on a huge scale. At least 250000 people starved to death. By 1989 the International Committee of the Red Cross (ICRC) was finally given authorisation to airlift food and medical supplies to the main southern towns of Wau, Juba and Malakal, all effectively under siege by the SPLA.

The 150000 or so people of Wau were sad, tired, and hungry having suffered starvation, large scale intertribal violence, and massacres by the army. In the refugee camps huddled and unsanitary conditions led to high incidence of diarrhoea and other infections, frequently leading to death.

\section{What did I do?}

I was a member of a four person team from Médicins San Frontières. There was one other doctor who was to work in and try to rejuvenate two primary health care clinics and run a small HIV prevalence survey. There was also a nurse whose role was in training and motivation of staff in the hospital and the implementation of the vaccination and therapeutic feeding programmes. Finally there was a builder to carry out various renovation works to the hospital and health centres and to supervise the vaccine cold chain. As a paediatrician in the government hospital my aim was to improve services in the children's ward and morale in the rest of the hospital. As the main hospital for the region the Correspondence to:
Dr Williams.

Accepted 5 November 1991 (Arch Dis Child 1992;67:330-2) Wau hospital was designed for up to 500 patients and 30 doctors. When I arrived there were little more than 100 occupied beds supervised by five local doctors who had mostly lost interest as a result of the general decline in morale that had taken place. Most of the medical work was done by minimally trained medical assistants who had few facilities, equipment, or drugs. Corruption was rife with most government supplied drugs soon finding their way to the marketplace. With the knowledge gleaned from previous involvement of Médicins Sans Frontières, the staff of the paediatric ward had already developed a degree of organisation that helped them to contribute significantly to the control of a seasonal epidemic of meningococcal meningitis that was rife when I arrived. In the hospital alone we treated 150 cases with a $10 \%$ mortality while hundreds more were occurring in and around town with much higher losses. This was also a good time to reactivate the vaccination programme in Wau for which a structure and staff still existed but, inevitably, refrigerators and generators did not work and all the vaccines were spoiled. With technical support and supplies from Médicins Sans Frontières and UNICEF the vaccination programme was recommenced with a vaccine campaign for meningococcus serogroups $A$ and C for 50000 people. Subsequently with further support and encouragement the programme of childhood and antenatal vaccinations was successfully recommenced.

I had intended to spend as much of my time as possible on the paediatric ward in teaching, training, and generally organising. Inevitably, however, a lot of time was taken up with management of individual cases. Initially malnutrition was the biggest problem. We built a grass roofed kitchen area before the onset of the wet season and from here we fed about 120 children daily with milk powder/wheatflour porridge and bean stew. Children were entered into the feeding programme on the basis of being less than $80 \%$ optimal weight for height. The worst cases were admitted to the ward for further supplementation with high energy milk (milk powder/sugar/oil) with the weaker ones sometimes being fed via nasogastric tube. A similar number of childern were also fed with weekly rations. Monthly rations were being delivered to tens of thousands of people by the ICRC who, additionally, organised daily feeding for several hundred children in the refugee camps. By midsummer, with a reasonable local harvest and some overland food movement allowed by a temporary ceasefire to supplement the air lifted supplies, the nutritional situation had improved considerably. 
The simple childhood infections also caused much morbidity and mortality. The three local medical assistants were seeing up to 100 outpatients daily and we had up to 30 inpatients. Common causes for admission were severe diarrhoea, malaria, and pneumonia. Various wasting illnesses were common in addition to starvation: tuberculosis, kala-azar, and almost certainly HIV infection, the prevalence of which was between $2 \%$ and $10 \%$ in various populations surveyed. Neonatal tetanus was a frequent and difficult problem; burns and trauma were common as were leprosy and onchocerciasis. By the end of my stay the ability of the nurses, medical assistants, and myself to recognise and treat most of the common problems was improving.

Our drug supply was flown in from Khartoum, mostly in the form of standard emergency kits supplied by UNICEF. On the ward we could use intravenous drips and nasogastric feeding as well as facilities to perform minor operations (usually draining abscesses) under intravenous anaesthesia with ketamine. I was also able to provide some medical input to two clinics run by Catholic nuns. My colleague from Médicins Sans Frontières was supporting two other such clinics and the ICRC had two or three nurses running dispensaries in the various refugee camps.

After the military coup in Khartoum in June 1989 the situation became more difficult; fighting recommenced and the government became less cooperative with the relief effort to the extent of withdrawing authorisation for the ICRC airlift in October. The project continued but without supplies from Khartoum could not remain effective. I left in December and the two last team members were withdrawn in February 1990. The situation since then has deteriorated further. Despite the need being even greater, with seemingly less government cooperation and world attention focused elsewhere, the ability of the various aid agencies to help has declined.

\section{What did I learn?}

Most obviously, although not necessarily most importantly, I gained experience by seeing and treating a vast array of diseases that I would be unlikely to see in the UK. I learned about many new illnesses from personal experience and from teaching by local people. I learned by having to manage and 'make do' with meagre resources using simple, locally available technology. For example, how to use BCG vaccine as a diagnostic tool when tuberculin purified protein derivative is unavailable or how to optimise the formulation of a high energy milk for both children with marasmus and kwashiokor with their different needs. I learned to work in a team at various levels, within the whole town with the local authorities and other aid workers, within the hospital with the local doctors, and on the ward itself. Here staff motivation was crucial and differences of opinion, no matter how seemingly trivial, particularly between members of different tribes could become so heated. Probably the most important lesson came from having to be constantly aware of the health needs of an entire community. In the UK one's working objectives are usually fairly clearly defined especially when involved in day to day patient care. In Africa it was most important to think in terms of one's influence on the entire health care system rather than just the individual patient; thinking about nutrition, vaccination, sanitation, and education which are all too easily forgotten in the UK. One had always to be aware of the consequences of each everyday action and in particular to be careful not to introduce any practice or technology that the local people would not be able to sustain.

Not only did I learn from a professional point of view but also from a personal one. Witnessing the kind of suffering that was taking place was not pleasant but seeing how well, stoically, and even happily that so many people coped with their lot was an enriching experience.

\section{What did I contribute?}

This is a difficult question to answer. Curative work was satisfying for me but without doubt the most useful contribution that the well trained expatriate can make is in the field of training, passing on the skills that he has been fortunate enough to learn. Such a role would be better filled by members of the local community who had been appropriately trained, but in developing countries suitably (and thus expensively) trained locals are likely to remain in short supply for the foreseeable future leaving a need for expatriate workers.

What are the problems of going?

It can certainly be unsettling. Several months had passed before I felt settled at home and at work. I had also to fill in with several months of locum work before I could find a suitable career registrar post. I wonder whether job interview panels consider such experience interesting but perhaps not quite as serious as a period at home or abroad in a research institution. For me, although obviously not for everyone, developing world experience was equally serious but more rewarding.

\section{What preparation is needed?}

There are many organisations through which one can find work in the developing world, many of which have trouble recruiting motivated volunteers. The Bureau for Overseas Medical Service Newsletter is a good place to start looking. The more experience gained before going abroad the better, but this has to be balanced against the greater difficulty of taking time out from higher up the career ladder. Junior registrar level is probably a good time to go, ideally having done one of the three month diploma courses in tropical medicine and hygiene at the London or Liverpool schools.

I have no doubt that the huge problems faced by the developing world can only be resolved by international political and economic reform and not by individual effort no matter how well 
meant. However, by working in the developing world we can improve our own understanding of, and more readily empathise with, the problems of others, perhaps help a little to resolve some of their suffering and in the process learn a great deal that will be of personal and professional value in years to come. I would urge any doctor who feels motivated towards working in the developing world to take the plunge. The benefits are enormous.

Commentary

Dr Williams' experience of a period in the Sudan will bring back memories to many others who have had the privilege of helping for a period in the developing world. I was, however, sorry he did not have the opportunity to visit the resource centre set up specifically to help such individuals at the Centre for International Child Health in the Institute of Child Health.

Since Professor Andrew Tomkins has taken over the responsibility of the unit, the material in the resource centre has been extended and is being updated. Paediatricians going overseas will always be welcome.

DAVID MORLEY Institute of Child Health 30 Guilford Street, London WCIN IEH

\title{
Measuring compliance with inhaled medication in asthma
}

\author{
J A P Coutts, N A Gibson, J Y Paton
}

\begin{abstract}
Using an electronic inhaler timer device (Nebulizer Chronolog), compliance with the prescribed frequency of inhaled prophylactic medication in 14 asthmatic children was measured. Underuse occurred in $55 \%$ of study days while overuse occurred in only $2 \%$. Such devices provide an important new tool for investigating inhaled drug compliance.
\end{abstract}

Asthma continues to be a major and rising cause of morbidity in childhood, ${ }^{1}$ despite advances in drug treatment and escalating presciption of antiasthma medication. ${ }^{2}$ Poor response to treatment may occur for many reasons but one increasingly recognised problem is failure to adhere to the prescribed treatment. This may be especially important in asthma where good symptom control often depends on the patient taking regular preventative medication.

Previous studies in asthmatic subjects have pointed to poor compliance with treatment. However, the methods described have either been indirect, such as prescription uptake, or have averaged the effects of drug taking over time as with monitoring drug concentrations.

More recently, inhaler timer devices have been developed. One example, the Nebulizer Chronolog (Forefront Technologies Inc, Lakewood, Colorado), electronically counts and times each actuation of a metered dose inhaler (MDI). This device replaces the normal plastic inhaler holder (figure) and can be used with all types of aerosol canisters allowing direct monitoring of inhaler use.

\section{Methods}

We used the Nebulizer Chronolog in a pilot Dr Paton.

(Arch Dis Child 1992;67:332-3) study investigating compliance with inhaled prophylactic treatment in children $(n=14$; age 9-16 years; M:F 6:8). All had moderate to severe asthma, were using MDIs, were being treated with prophylactic inhaled corticosteroids, and were judged to have satisfactory inhaler technique. Verbal consent for the study was obtained from the children and their parents. All were aware that the device would 'count' the number of actuations but, in general, were not aware of the precision of the recording. The subjects were issued with an initialised Nebulizer Chronolog and a diary card with instructions to score their daily symptoms and note their inhaler use.

After one to three months the Nebulizer Chronolog and diary cards were returned. The information stored in the device was read and analysed by dedicated computer software and a report, detailing medication use, prepared. For each individual patient day, the prescribed use, recorded use (Nebulizer Chronolog), and reported use (diary card) of prophylactic medication were compared. A 'compliant day' was defined as one in which the prescribed number of puffs were taken at appropriate times.



A Nebulizer Chronolog compared with a standard metered dose inhaler. 